tissue and bone, invasion of the lymph glands and infections of the genito-urinary system. Wright's results in these usually intractable cases are so good that he says:-

In view of the very favorable and. what is almost more important, uniformly successful results which can, as will have appeared, be obtained even in the most intractable cases of localized tubercular infection by the therapeutic inoculation of tuberculin carried out under the safeguards explained above; and in view of the fact that not less favorable results can be obtained in connection with the treacment of other localized infections by the aid of the corresponding bacterial vaccines, I do not hesitate to contend that we have, in the power of raising the antibacterial power of the blood witli respect to any invading microbe, out of all comparison the most valuable asset in medicine. I would, in riew of this new asset in medicine, fain induce the surgeon to abate something from his conviction that extirpation and the application of antisepties offer in connection with bacterial infection the only possible means of cure. I would have the surgeon resort to extirpation only when the physician tells hin that all other means have been exhausted; and I would have the physician assume everywhere the role of an immunisator; and would have him defer handing his patients over to a surgeon before he has tried in every case of localized bacterial infection which is unassociated with immediate risk to life the therapeutic inoculation of the appropriate bacterial vaccine.

With this mass of evidence before us we must admit that tubcrculin therapy is in accord with the modern theories of immunity; that theoretically tuberculin is capable of increasing the natural defenses of the organism when given in the proper doses at proper intervals, and that clinical experience in its administration warrants a more general use of it in combating tubercular infection.

\section{CONSERVATIVE SERGERY OF ARMS AND LEGS.}

JOHN EGERTON CANNADAY, M.D.

Surgeon-in-Charge Sbeltering Arms Mospital. HANSFORD, W, VA.

The simplest way to treat a badlv injured limb is by amputation, but the simple and direct method if it involves too much sacrifice may not always be best for the patient. In certain cases amputation is slightly safer, as the attempt to save the limb may be attended with some danger to the patient, while amputation shortens treatment and conservative treatment is tedious and may extend over many months. What patient will not willingly accept a small chance of risk to life rather than the certainty of loss of limb? In times of such great national calamity as war when available hospital space is overcrowded, when proper nursing and dressing are at a premium, many limbs must, of necessity, be sacrificed. At such times both more radical and more conservative surgery must often be practiced than would be deemed desirable in times of peace.

Great stress has recently been laid by Reclus and other French surgeons on the value of systematic conservatism in the treatment of injuries of the extremities, some of them going so far as to lay down the rule that no primary amputation should be done. They believe that bleeding points should be ligated, the injured parts irrigated, dressings applied, the general condition of the patient looked after and amputation, if needed, done later when the patient has recovered from primary shock and has accumulated strength with which to combat the dangers of anesthetic and operation. Whenever the circulation of a part distal to the injury is at all fair, there is surcly considerable reason for belicving that the limb can be saved. The brilliant work of Carrell and Guthrie in the anastomosing of blood vessels gives promise of something better in the future than has been known in the past for limbs whose main vessels have been divided. The restoration of continuity of tendon and nerve has given most signal functional re. sults in many cases. Fxtensive laceration of the soft tissues combined with comminuted or other serious fractures constitute a most serious condition and one that will tax the care, the ingenuity and the skill of the surgeon in his attempt to restore anything like a normal condition. The young and healthy individuals will have chances for a restoration of the circulation by the collateral ressels far in excess of the older patient whose circulatory capabilitics are on the retrograde. Both the radial and ulnar arteries of the forearm may be severed and yet the circulation be sufficient to save the limb; the femoral artery has been severed and yet the collateral vessels maintained the life of the member. In all accident cases I try to give the patient the benefit of the doubt and make an earnest effort to save the limb. though it not infrequently happens that I liave to resort to amputation later. By carefully watching the patient and by the exercise of surgical judgment but little risk to life is assumed by the waiting. Prior to $187 \%$ amputation after compound fracture was the universal rule. Volkmann was the first to secure satigfactory results by other means.

The application of a tourniquet often seriously impairs the vitality of the part, especially so if the constrictor remains in position for any considerable length of time. It is an easy matter to pick up and ligate most bleeding points. A compress held in place by a handage will control most cases of blecting. When possible to aroid it the tourniquet should not be used, as the deprivation of blood supply to the distal part entailed by its use exercises a most malign influence on the tissues. The skin may be almost entirely stripped from a limb and ret the chances for restoration be excellent because the blood ressels are uninjured. No matter how large the defect, the covering can be restored by skin grafting. It is always best to delay operation until preparations can be made to do the work by a carefully planned and perfected technic. Two or three dars' waiting can hardly do harm provided the limb is propcrly looked after. Many advantages may be obtained by this delay. The patient has ample time to recover from the primary shock and we can tell almost to a certainty whether or not amputation is required.

Do not probe or disturb the interior of the wound before applving first-aid dressing. If this does not control the blceding, apply tourniguet and blanket splint and get the patient to the operating room. The ordinary methods of cleansing pursued are prone to carry much new infective material into the wound. Scrub from, not toward, the wound, be careful not to allow soap, water or other solutions to run into the wound while the limb is heing cleansed. Turpentine, gasolin, benzin or soap and water followed by alcobol or ether are all effective and their varying use is only a matter of choice. Tiastly I apply to the limb 0.5 per cent. iodin solution. $\mathrm{I}$ irrigate the wound thoroughly with hot normal salt solution.

If the circulation is good and the condition of the patient warrants it, the fractured ends of the bones are united by suture, 30-day chromicized catgut of large size. No. 3 being preferred. If wire is used, it should be romoved after it has served its purpose, for the reason that any foreign body left in the tissues, of necessity, 
acts as an irritant. Bronze wire is the best, laving great tensile strength; iron wire is fair, but silver wire is too brittle to be of service. Severed tendons are sutured, drainage provided for and splints applied. On the other hand, if the vitality of the part is at all endangered there should be just as little interference as possible: useless manipulation may cause much injury to the soft tissues by the cutting done by the sharp fractured ends of the bone. Drainage should be provided, the wound irrigated and the bones held in place by traction or splints or both. Tendons, nerves and bones are better sutured some time later after the circulation of the part has been restored in a measure.

When the fracture is comminuted or oblique, simple wrapping is probably one of the most effective methods of holding the fragments in proper position. Plating is an excellent method of trating some varieties of fracture. All detached bone fragments should be removed, as they will otherwise act as foreign bodies and promote suppuration. Whenever possible the periosteum should be preserved so that regeneration of bone may take place. The wound should be carefully searched for bits of foreign material. and one should see that no soft tissues are interposed between the ends of the bones. When there has been much dirt contamination it is well to give an immunizing dose of tetanus antitoxin as a safeguard.

The after-care of these cases is a great tax on the technical skill and ingenuity of the surgeon. Splints and other appliances for immobilization are too numerous to mention or discuss, a sad commentary on their unsatisfactoriness. The problem of immobilization requires much ingenuity, since no treatisc, however complete, can give directions that will cover every contingener that may arise. The varied requirements are practically innumerable. Prevention of motion with fair approximation and apposition of the bone ends must be secured if possible. Frequent changing of the splint in compound fractures has its serious disadvantages and should be overcome if possible. Where there is much mobility an excessive amount of callus will form and may include and press on some important nerve trunk. A fenestrated plaster dressing suits many of these cases and it can be protected from the wound discharges by some of the numerous methods in vogue. A few of these cases, those that are strictly clean and can be kept so, are better off without drainage. Most are infected either by the accident or the treatment, as the opportunities are many and the susceptibility great. Men doing referred practice sometimes blame the physician who gave the first aid for the infection. The wound is often infected before the case is seen by a physician, the conditions often being such that infection is unavoidable, being carried in at the time of the accident from the skin or clothing or from the traumatic agent.

Most of these cases need drainage, and gauze strips are usually effective except for hemostatic purposes. Rubber tubing (split or fenestrated) is not only satisfactory as drainage, but is a great convenience when we wish to irrigate the wound. These drains should be placed, whenever possible, so as to get the assistance of gravity. Infected wounds should have ample provision for drainage and irrigation. When there has been extensive laceration of the skin and muscles it is best not to attempt to close the wound completely. There is great liability to suppuration because of the lowered resistance of the trammatized tissues and br reason of the excellent culture media furnished by the extravasated blood and serum and the frequency of initial infection.
I have discontinued the use of peroxid of hylingen and have never used a bichlorid of mercury solution in the irrigation of wounds. $1 \mathrm{am}$ satisfied that both promote rather than decrease wound secretion. Warm normal salt solution is a good mechanical cleanser and is non-irritating to the tissues. A weak solution of iodin is possessed of a maximum bactericidal power combined with a minimum toxic and irritant effect. It not only has a destructive effect on pus germs, but to a great extent will seal the ends of the lymphatic and blood vessels against the absorption of septic material.

The fractured ends of the bone may give trouble by necrosis, in which case the necrosed bone mav be remored from time to time without much difficulty. In gangrene without infection amputate at the point of fracture and regulate those of the stump later. In gansrene with infection removal of tissue must be radical and extensive. The after care of many in these cases is tedious and prolonged. Necrosed bone will have to be removel from time to time. There will often be chronic suppuration and the patience of both operator and patient will be severely tried. In cases in which trauma lias been severe sloughing will usually be extensive and infection almost certain. Antiseptic solutions should not be used on bone, as they are very destructive to the periosteum.

There are certain disadrantages that may accompany the retention of crippled limbs, such as contractions of tendons and fascia, ankyloses of joints, chronic edema from inclusion of blood ressels in callus or scar-tissue, and disturbances of innervation from pressure on nerve trunks, and the treatment is lengthy and expensive. On the other hand, the expense of an artificial limb is saved, contractions and joint stiffness may be largely prevented and overcome by passive motion. Complete ankylosis has been relieved and the joint made mobile by the plastic interposition of fascia between the bone ends, brilliant results have been achicved in nerve surgery cren after the lapse of many years from the time of the accident, and tendons are transplanted or anastomosed with easc. True. amputation gives in most cases far quicker results, but who does not prefer the arm or leg God gave to some clumsy device contrived by man?

Tramma of joints is often followed by infection. Open treatment by irrigation and packing with iodoform gives good functional results, though ankylosis is apt to result. There is an increasing tendency on the part of men who have successful technic to resort more and more to the open treatment of joint injuries and fractures. Bier's method for the production of artificial hyperemia has saved many joints from resection.

With a view to the illustration of the deductions I have made from a study of the subject I have selected the following from a large number of that class of cases; all were notably bad and looked to be fit subjects for amputation:

CASE 1.-D. M., male, aged 22, was referred to me by $\mathrm{Dr}$. C. N. Watts, Dothan, W. Va.

History.-The man had been shot in the left leg at about the junction of the upper and middle thirds by a Winchester rifle; the ball struck the tibia squarely and produced a badly comminuted fracture. An occlusive dressing with splints was applied and the man kept in his shanty in a railroad camp with the hope that healing would take place. After six weeks of this, suppuration not only of the wound but of the entire leg below the knee had become so general that amputation was considered to be the only means of saving the man's life. At the time the patient came to the hospital he had severe chills, fever and sweats, but I decided to make an attempt to save the leg. 
operation.-Wuder general ether anesthesia the wound was opened, cleansed and several fragments of dead bone removed; four long pus cavities were opened freely, irrigated and drained. These cavities lay in general in the direction of the muscle planes and were connected by sinuses with the original wound. One of them extended some distance above the linee joint into the thigh. Neither the ankle nor knee joints were involved. Under frequent dressings and irrigations some improvement of the leg was manifested, but during the next three months the patient had to be twice anesthetized and new sinuses opened.

Result.-At the end of the tenth week after admission to the hospital, the sixteenth week after the receipt of the injury, there was bony union and the patient was put on crutches. In a month he was walking in a limping manner, but the original bullet wound had not yet closed. The leg was painful when muct used. Two subsequent operations had to be done for the removal of carious bone. These cavities finally filled and at the end of the tenth month of hospital residence he left. well, with a straight, sound leg, capable of earning his own living and not likely to become a public eharge.

CAse 2.-D. A. P., male, was referred by Dr. J. R. Pharr, Dunloop, W. Va.

History.-This man had received the full load of a shotgun at short range in the region of the great trochanter on the left side, a large part of the load entering below that point, producing a comminuted fracture of the femur. The shaft of the femur was split by an oblique fracture eight inches long. The outer portion of the trochanter was shattered and the neck of the femur split in half, the separation extending inward as far as the head of the bone. The injuries to the soft structures were most extensive. the flesh being badly lacerated and torn. Shotgun wadding. bits of clothing and fragments of bone were nost plentiful in this wound.

Operation.-My first thought was to do a hip-joint amputation, but I decided to try more conservative treatment. Considerable time was spent in suturing the bones into some sem. blance of their former shape. The wound was put in as good condition as possible, iodoform gauze was plentifully packed into the gaping cavity and a long well-padded side splint applied. Great care was taken to prevent wound suppuration Union was good, the injury to the muscles filled by granulation, and the patient left the hospital at the end of the ninth week, well.

Case 3.-F. B., male, aged 21, a saw mill employé.

History-Patient fell so that his loft arm came in contact with a rapidly revolving circular saw. Two and one-half inches below the elbow the forearm was more than two-thirds sawn in two. The radius was cut entirely in two and the articular end of the ulna was torn completely out of the elbow joint and projected backward past the angle of the elbow for at least two inches. He was brought to the hospital about three hours after being injured and was operated on soon afterward.

operation.-The wound was irrigated with saline solution, the fractured ends of the radius were wired, and the elbow luxation was reduced. The wound was closed with the exception of a small drainage opening and the arm immobilized in a right angled splint. Healing was primary and passive motion was begun at the end of the second weel. Results were perfect and the man now has a normal arm with no elbow ankylosis whatever.

Case 4.-G. H. W., Olcott, W. Va., was referred to me by Dr. W. W. Tomplins, Charleston, WV Ta.

History.-This man had been severely struck on the left elbow in an accident. The arm was terribly swollen, crepitation in region of the elbow joint could be made out and not much else.

Operation.-I made an incision lateral to the joint and found that the component bony parts of the joint had been crushed. I resected the broken end of the ulna, also the articular head of the humerus, which was fractured entirely across its diameter. Through and through drainage was maintained for a time. A useful arm capable of a considerable range of motion was the result.

CASE 5.-H. B. was referred to me by Dr. S. M.I. Stone, Hugheston, IV. Va.
II istory.-The patient had a Pott's fracture of the right Ing, also a compound fracture of both tibia and fibula about the junction of the upper and middle thirds. The injuries to the soft tissues were extensive, there being large lacerations and ecchymoses.

Treatment.-The wound was drained and the bones held in position by splints. A large area of the skin sloughed. Edema of the ankle and foot was severe and persistent, and associated with the formation of blebs. The bones finally united, the uncovered areas were repaired by skin grafting, and six months later the patient possessed a fairly useful limb.

Case 6.-C. H., white, adult male, victim of a mine accident, referred by Dr. J. F. Bowles, Ward, W. Va., had a compound fracture of both bones of the leg midway between knee and ankle, with extensive lacerations of skin and muscles; the lower end of the tibia was projecting from the wound.

Treatment.- The wound of four or five hours' standing was irrigated and the displaced bones reduced. Splints were applied. Despite the use of splints and extension it was impossible to keep the bone ends in apposition. A veek later the bones were united by suture and rubber tube drainage through the leg was established. There was considerable sloughing of the soft structures and an area of four inches of the anterior surface of the tibia was exposed. The bone surfaces were rapidly covered by granulations until only an inch of the lower fragment was bare. There was considerable infection. The temperature for the first ten days often reached $103 \mathrm{~F}$. in the afternoon, later it seldom rose above $100.5 \mathrm{~F}$, and by the end of six weeks it had reached normal. At the beginning of the thirteenth week the patient had a severe chill and his temper. ature suddenly rose to $104 \mathrm{~F}$. Two days later a beginning abscess was discovered in the calf of the leg and opened. Union was then excellent and the patient was able to bear considerable weight on the leg when walking. Thirteen weeks after the original injury a piece of necrosed bone 3 inches long by $11 / 4$ : inches wide at the upper end and $1 / 2$ inch wide at the lower end was removed from the lower fragment of the tibia. The wound is nearly healed and except for a little stiffness in the ankle joint the prospects are good for complete recovery.

\section{CONCLUSIONS.}

1. The conservative treatment of severe injuries to the arms and legs is essentially modern, and we should not do primary amputations (except in case of a limb held by only a few shreds), but wait for shock to pass and for the patient to regain strength.

2. We should avoid the use of antiseptic solutions for irrigation and use instead normal salt solution.

3 . Bones should not be permanently sutured and we must not be in too great a hurry nor attempt too much in the beginning.

4. Moist gangrene calls for radical treatment.

5. Drainage is usually necessary and the rubber tube is to be preferred.

6. Good functional results may be obtained against great apparent odds, and a saved limb is preferable to an amputation stump.

Therapeutic Power of Mental Effort.-Dr. F. T. Seybert, Council Bluffs, Iowa, states that the therapeutic power of mental remedies is best illustrated in the treatment of functional nervous disorders, especially when associated with mental symptoms. A natural susceptibility, which is one of the strongest factors in the etiology of these disturbances, becomes, when judiciously managed, a means by which curative action can be aroused-so sure is Nature in compensa. tions. In neurasthenia, above all other diseases, there is no prescribed routine of treatment; its diverse causes and varied nature would prohibit this. All remedies which have any bearing and all influences are sometimes needed, and he who has the clearest insight and the most ingenuity in devising ways and means will be the most successful. A change of occupation is often beneficial, and in all cases of long dura. tion employment of the mind is essential.-Iowa Med. Jour. 